\title{
Solar drying and sun drying as processing techniques to enhance the availability of selected African indigenous vegetables, Solanum aethiopicum and Amaranthus lividus for nutrition and food security in Uganda
}

\author{
Maria Bisamaza ${ }^{1}$ and Noble Banadda ${ }^{2 *}$ \\ ${ }^{1}$ Food Technology and Nutrition Department, Makerere University, P.O. Box 7062, Kampala (Uganda) \\ ${ }^{2}$ Agricultural and Biosystems Engineering Department, Makerere University, P.O. Box 7062, Kampala (Uganda) \\ *Corresponding Author Email: banadda@caes.mak.ac.ug
}

\section{ABSTRACT}

\begin{abstract}
The purpose of the study was to compare sun drying and solar drying as processing techniques to prolong the shelf life of African Indigenous Vegetables while preserving the nutritional quality. The two vegetables selected for the study were solanum aethiopicum (locally known as Nakati) and amaranthus lividus (known as Bbuga) because they are common staple vegetables and cheap and accessible to many people in Uganda. The fresh samples were tested for microbial load using the power plate technique. The sliced vegetables for sun drying and solar drying were sun dried and solar dried for 48 hours each and packaged in air tight polythene bags and stored at room temperature for up to 8 weeks. Ascorbic acid tests were also carried out using the titration method by Kirk and Swayer (1991) on fresh samples and on each pre-treated sample of each vegetable under study. Amaranthus lividus exhibited an intense colour which masked the end point. The results got were analysed using Gen stat as a statistical package using a $5 \%$ level of significance. The obtained results showed that there was a significant difference in the ascorbic acid content of the fresh samples, sundried samples and solar dried samples of the solanum aethiopicum. Fresh samples of the solanum aethiopicum had significantly the highest ascorbic acid content followed by the solar dried samples and finally the sun dried samples had the least ascorbic acid content. Furthermore, there was significant difference between the microbial loads for the fresh samples, sun dried samples and solar dried samples of amaranthus lividus and solanum aethiopicum. The fresh samples had the significantly highest microbial load followed by the sun dried samples and lastly the solar dried samples had the least microbial load. There was a significantly higher microbial load in the amaranths lividus than in the which solanum aethipicum could be attributed mainly to the larger surface area and handling. There was no pattern observed in the microbial load over the eight weeks of storage for both the solanum aethiopicum and amaranthus lividus.
\end{abstract}

Keywords: Leafy vegetables, Sun drying, Solar drying, Postharvest handling and Microbial load.

\section{INTRODUCTION}

Indigenous vegetables are those plants whose leaves and aerial parts have been integrated in a community culture for use as food over a long period of time. (Fox and Young, 1982; Chweya, 1977; Shippers, 2000; Ndoro 
et al., 2007). Uganda is a home to hundreds of African indigenous vegetables whose overall potential is hardly being used. Some of the indigenous vegetables that are commonly cultivated and consumed in Uganda include species within the genera Amaranthus, Celosia, Cleome, Bidens, Crassocephalum, Solanecio, Stuchium, Launea, Vernonia, Brassica, Eruca, Lepidium, Roripppa, Citrullus, Coccinia, Cucumeropsis, Cucumis, Kedrostis, Lagenaria, Mmordia, Telfairia, Gnetum,Plectranthus, Solenostemn, Crotalaria, Cyamopsis, Lablab, Psophocarpus, Senna, Sphenostylis, Tylosema, Abelmoschus, Hibiscus, Sesamum, Ceratotheca, Portulaca, Talinum, Solanum, Corchorus, Triumfetta, Asystasia, Cyphia and Ensete (Goode, 1989; Rubaihayo, 1994).The main production areas are Kabale, Kamuli, Kapchorwa, Kasese, Mbale, Masaka, Mubende, Mukono, Wakiso, and the West Nile regions. There is increasing awareness of their nutritional value by consumers and demand including in dynamic markets such as supermarkets. Consuming 100 grams of an African vegetable is believed to provide $100 \%$ of your body's daily micro nutrients. The traditional vegetables are high in Vitamins A, B and C, proteins and minerals such as iron, calcium, phosphorus, iodine and fluorine. However, the use of these vegetables is mainly as part of cultural heritage as a delicacy, playing a significant role in customs and traditions and in maintaining the equity within the family structure. According to COLEACP (2006) the fruit and vegetable sector generates a lot foreign exchange in Uganda. Most of the fruits and vegetables produced in Uganda are consumed locally while the rest are transported to rural markets for local consumers or are bought at the farm by neighbours and others are transported to bigger market centres (Sonko et al., 2005). In Uganda, vegetables are underutilised; their production system is regarded as an informal production activity managed outside conventional market and economic channels, and has unfortunately been neglected by agricultural research and development. Majority of Ugandans do not consume adequate amounts of traditional vegetables to meet their daily requirements of vitamins, minerals and proteins and even of what is consumed a large proportion (20-50\%) of these nutrients is lost from garden to table. The losses may be physical, bio-chemical and nutritional. Vitamins are essential nutrients for all especially pregnant women, children and the sick. It has been estimated that up to 65,000 children in Uganda die every year due to vitamin deficiency (UDHS, 2001). African indigenous vegetables have been found to have a very high nutrition value and consumption of $100 \mathrm{gms}$ of fresh weight vegetables may provide up to $100 \%$ of daily micronutrient requirements and $40 \%$ of the protein daily requirements and so increased consumption would help reduce deficiency related health complications. African vegetables are however subject to some deteriorative changes that are be undesirable to consumers and retailers as they compromise the quality of the produce Bruhn (2002) as well as reduce the shelf life thus reducing the availability of these vegetables. To increase availability one needs to control the physical, chemical and biological deterioration. The vegetables need to be processed to prolong their shelf life and availability beyond seasons and geographical location. The deteriorative processes cannot be stopped but can be controlled and if properly preserved, high quality produce at table can be ensured. Among the ways of preservation is dehydration which can be done by solar drying and sun drying among others. These reduce the water activity in turn controlling deteriorative reactions. However, this exposes the vegetables to heat and ultra violet rays that reduce heat and light sensitive nutrients like Vitamin $C$. So a compromise has to be drawn between the technique that prolongs the shelf life while also preserving the heat and light sensitive nutrients. The target is vegetables because of their high micro nutrient content plus the fact that their growth does not require a high investment as they are strongly adapted to their natural growing conditions and are a staple food for many Ugandans. African Indigenous vegetables are highly sensitive to acid, air, light and heat and will undergo deterioration immediately after harvest reducing their shelf life. Due to the perishability and seasonal availability one has to process vegetables to prevent both enzymatic and microbial spoilage in order to encourage all year production. This study aims at comparing sun drying and solar drying techniques of processing to see if there is a significant difference in the extent of preservation of the nutritional and microbial quality and therefore the shelf life of the vegetables in the long run acting as a good tool to control food and nutrition insecurity.

\section{MATERIALS AND METHODS}

\section{Experimental Design}

The study was carried out in two parts; first of all, the ascorbic acid in both solanum aethiopicum (Nakati) and amaranthus lividus (Bbugga) of samples that are fresh, solar dried and sundried were compared and secondly, the total plate count on both solanum aethiopicum (Nakati) and amaranthus lividus (Bbugga) of samples that are fresh, solar dried and sundried were also evaluated and compared. Fresh solanum aethiopicum (Nakati) and amaranthus lividus (Bbugga) was selected randomly to reduce any bias from the same trader in Nakasero market (Kampala, Uganda) in two separate batches. The vegetables were bought at 6:00 a.m in the morning to avoid any sun drying on the day they were to be pre treated. The samples were packed in black polythene bags to keep off light and transported by road immediately to the lab that was fifteen minutes away. Chemical reagents used were 2,6 -dichlorophenolindophenol (DCPIP), trichloroacetic acid and standard 
ascorbic acid for ascorbic acid analysis and plate count agar, sodium chloride and peptone were used for microbial analysis. They were all of analytical grade. The vegetables on arrival to the lab were immediately washed with clean portable water and chopped using a clean stainless steel knife into approximately $4 \mathrm{~mm}$ slices. The chopped vegetables were divided into three portions; the fresh which were not further treated but taken straight to the laboratory for ascorbic acid and microbial tests, the sun dried that were spread on a clean sack and placed under direct sunlight for forty eight hours (they were carried in doors at night) and the solar dried that were spread on the clean solar drier trays and left to dry for forty eight hours. The solar dried and sun dried portions were double packaged in polythene bags and the package was then air tight sealed and labelled to indicate the type of vegetable, the pre treatment and the week when it will be tested to prevent any errors.

\section{Laboratory Analysis}

\section{Total plate count}

The total plate count was determined by pour plate method using plate count agar according o AOAC (1999). This was carried out from day zero and every seven days during a storage period of eight weeks. Ten grams of the sample was weighed, placed into $90 \mathrm{mls}$ of diluents and shaken. $1.0 \mathrm{ml}$ of the solution was pipetted into a $9 \mathrm{ml}$ dilution blank of $\left(10^{-2}\right.$ dilution). This was repeated until a $10^{-10}$ dilution. $1.0 \mathrm{ml}$ was got from each of the $10^{-4}, 10^{-6}$, $10^{-8}$ and $10^{-10}$ dilutions and were each placed in identical sterile petri dishes and molten agar cooled to $42-45^{\circ} \mathrm{C}$ was added and mixed thoroughly and left to solidify. This was done twice for identical treatments and each was done in duplicates. A label with the type of vegetable, the treatment and the dilution was also indicated on each petri dish. The petri dishes were then inverted and incubated for twenty four hours at $35{ }^{\circ} \mathrm{C}$. A control with just agar and another with diluent and agar were also incubated to test the sterility of both the agar and the diluent ensuring the vegetables are the only possible source of microbial growth. Only the duplicate petri dishes with growth of up to 300 were counted and recorded as cfu/ml (colony forming units per millilitre).

\section{Ascorbic acid content}

This was done using the titration method outlined by Kirk and Sawyer (1991) It was doe over a three week duration. Standard ascorbic acid $(0.04 \mathrm{~g})$ was weighed and dissolved to $50 \mathrm{mls}$ in a volumetric flask. The extraction solution had $5 \%$ Trichloroacetic acid which was made by weighing $25 \mathrm{~g}$ of the salt and dissolving in 500 $\mathrm{mls}$ with distilled water. The extraction solution was then filtered to stock solution using cotton wool and kept in a clean bottle. DCPIP $(0.05 \mathrm{gms})$ was dissolved in $100 \mathrm{mls}$ and then filtered to the stock solution. Ten millilitres of the stock solution were pipetted and diluted to $100 \mathrm{mls}$ in a volumetric flask. The DCPIP was standardised by titrating against $3 \mathrm{ml}$ of standard ascorbic acid. The standard ascorbic acid used was $0.8 \mathrm{mg} / \mathrm{ml}$ and $1 \mathrm{ml}$ of DCPIP was equivalent to $0.02743 \mathrm{mg}$ Ascorbic acid.Two grams of the sample was weighed, crushed in a mortar with a pestle using a $5 \%$ Trichoroacaetic acid extraction solution. The extract was filtered using cotton wool that was placed inside a funnel into a $50 \mathrm{ml}$ volumetric flask. $5 \mathrm{gms}$ of black charcoal was added to change its colour and it was then centrifuged at 7000 revolutions/minute for ten minutes to give a clear liquid whose end point is easy to read. $5 \mathrm{mls}$ of this clear solution was then pipetted and $3 \mathrm{mls}$ of the prepared extraction solution was added to it. This mixture was titrated with standardised DCPIP solution until the blue DCPIP solution turned colourless and the titre value was recorded. The amaranthus lividus (Bbugga) had an intense colour which after several different trials failed to disappear thus making the end point reading impossible. The different ways that were tried to reduce the intense colour include; decreasing the weight from $2 \mathrm{gms}$ to $1 \mathrm{gm}$ and then to $0.5 \mathrm{gms}$, increasing the black charcoal from $5 \mathrm{gms}$ to 7,10 and $15 \mathrm{gms}$ and increasing the centrifuge time from 10 minutes to 15 minutes and then 20 minutes. All these trials brought negative results as the intensity of the colour didn't reduce and given the limitations of my budget the overall ascorbic acid test for amaranthus lividus (Bbugga) was unsuccessful. However, the ascorbic acid test for the solanum aethiopicum (Nakati) was successful and the results were recorded. The data was analysed using Gen stat as an analytical package with a level of significance of $5 \%$.

\section{RESULTS AND DISCUSSION}

\section{Effect of the pre treatment on the microbial load of the vegetables under study}

The second part of the study involved laboratory analysis of microbial load of the pre treated vegetables stored at room temperature for up to eight weeks as shown in Table 1.

From Table 1, it can be noted that there was a significant difference between the fresh untreated vegetables and those that were sun dried and solar dried. For both the fresh amaranthus lividus and fresh solanum aethiopicum there was a significant reduction in the microbial count when they were sun dried and solar dried as compared to when they were fresh. This could be attributed to the reduction in water that is an essential nutrient required for dissolving nutrients and metabolism of these nutrients by microorganisms (Jay, 1986). There was a significantly greater reduction in the microbial 
004 Afr. J. Food Sci. Technol.

Table 1. Total microbial load (log cfu/ml) of pre-treated amaranthus lividus and solanum aethiopicum.

\begin{tabular}{lllllllll}
\hline & Weeks & & & & & & & \\
Treatment & 1 & 2 & 3 & 4 & 5 & 6 & 7 \\
\hline Bbugga Solar dried & 5.357 & 5.453 & 5.263 & 5.217 & 5.403 & 5.41 & 5.71 & 5.717 \\
Bbugga Sun dried & 5.583 & 5.68 & 5.34 & 5.387 & 5.603 & 5.777 & 5.867 & 5.803 \\
Nakati Solar dried & 5.103 & 4.763 & 4.913 & 4.59 & 4.837 & 4.963 & 4.72 & 5.2 \\
Nakati Sun dried & 5.47 & 5.387 & 5.203 & 4.827 & 5.07 & 5.493 & 5.333 & 5.57 \\
Grand mean & 5.378 & 5.321 & 5.18 & 5.005 & 5.228 & 5.411 & 5.407 & 5.5725 \\
LSD & 0.1698 & 0.5276 & 0.1905 & 0.2536 & 0.1569 & 0.1885 & 0.2185 & 0.06593 \\
\%CV & 1.6 & 5 & 1.8 & 2.5 & 1.5 & 1.7 & 2 & 0.6 \\
F-prob. & 0.002 & 0.025 & 0.007 & $<.001$ & $<.001$ & $<.001$ & $<.001$ & $<.001$ \\
\hline
\end{tabular}

Table 2. Ascorbic acid content of pre-treated solanum aethiopicum (Nakati) (mg/100).

\begin{tabular}{llll}
\hline & Weeks & & \\
Treatment & 1 & 2 & 6.995 \\
\hline Nakati fresh & 6.903 & 5.532 & 5.766 \\
Nakati Solar dried & 5.44 & 4.16 & 5.486 \\
Nakati Sundried & 4.16 & 5.562 & 4.16 \\
Grand mean & 5.501 & 0.3277 & 5.471 \\
LSD & 0.2073 & 2.6 & 0.2073 \\
\%CV & 1.7 & $<0.001$ & 1.7 \\
F-prob. & $<0.001$ & & $<0.001$ \\
\hline
\end{tabular}

count when the vegetables were solar dried as compared to sun dried for both the solanum aethiopicum and amaranthus lividus. From table 1, it can be observed that throughout all the eight weeks there was a significant difference $(<.001)$ at a significant level of $5 \%$ between the microbiological count between treatments of amaranthus lividus solar dried and amaranthus lividus sun dried and the solanum aethiopicum solar dried and solanum aethiopicum sun dried as indicated by comparing their L.S.D and the higher values. The results for amaranthus lividus showed that for all the eight weeks those that were sun dried had a significantly higher microbial content compared to those that were solar dried with a significant difference $(<.001)$ at a significant level of $5 \%$. Likewise the results for solanum aethiopicum showed that for all the eight weeks those that were sun dried had a significantly higher microbial content compared to those that were solar dried at a significant level of $5 \%$. This is probably because the solar drier heats the air inside to a temperature above that of the environment which is the temperature that the sun dried vegetables are exposed to. This ensures a faster and more effective drying process eliminating water that is an essential nutrient required for dissolving nutrients and metabolism of these nutrients by microorganisms (Jay, 1986). For both solanum aethiopicum and amaranthus lividus the microbial load significantly reduced when the fresh samples were solar dried and sun dried with a significantly greater reduction of the microbial load in the solar dried as compared to the sun dried. However, during storage there was no significant increase or decrease pattern in the microbial load over the eight weeks of storage for both the solanum aethiopicum and the amaranthus lividus as would be attributed to storage. This could be attributed to efficient packaging and storage conditions that do not favour contamination and growth. The results also showed a significant difference between the microbial contamination of the amaranthus lividus and the solanum aethiopicum right from the initial microbial load to post treatment for all the eight weeks. This is probably due to the larger leaf surface area and also for the same reasons microorganisms are also able to grow much faster. It could also be because of the growing conditions, harvesting conditions, sanitation and any damage to the tissues. Franci and O'Beirne (2002) also observed that the efficacy of the disinfection treatments were dependent on the vegetable type as well as its Microbial load.

\section{Effect of the pre-treatments on the vitamin c content of the solanum aethiopicum (Nakati)}

Table 2 summarizes the ascorbic acid content of pretreated solanum aethiopicum (Nakati). It suffices to mention that this treatment only focused on solanum aethiopicum (Nakati) because of time constraint.

The results in Table 2 showed that there was a significant difference $(<0.001)$ at a significant level of $5 \%$ indicated by Comparing their LSD and the higher values in the ascorbic acid content between treatments of solanum aethiopicum fresh, solar dried and sun dried. The results showed that the fresh solanum aethiopicum showed the significantly highest amount of ascorbic acid. 
There was a significant reduction in ascorbic acid when the vegetables were sun dried and solar dried with the significantly greater reduction in the solanum aethiopicum that was sun dried. This is probably because direct sun drying exposes the vegetables to greater solar radiation (ultra violet rays). Vitamin $\mathrm{C}$ is especially prone to oxidative destruction in presence of oxygen, light, enzymes, moisture and metal ions. On the other hand the covered solar driers screen out more ultra violet radiation and so it is able to retain more of the ascorbic acid. The amaranthus lividus did not have results on the effect of the various treatments on its ascorbic acid content because its intense colour masked the end point.

\section{CONCLUSIONS AND RECOMMENDATIONS}

\section{CONCLUSIONS}

Post harvest processing techniques influence the nutritional quality and microbial stability of fresh African Indigenous vegetables. The objective of this research was to compare the nutritional and microbial quality of solar dried and sun dried vegetables as means of increasing the shelf life of African Indigenous vegetables while preserving the quality. The fresh vegetables had the highest ascorbic acid. On solar drying the ascorbic acid significantly reduced but even more of the ascorbic acid reduced when the vegetables were sun dried. Therefore the solar drying technique of preservation retained more ascorbic acid as compared to the sundried preservation technique. The microbial load significantly reduced when the vegetables were sun dried but even a greater reduction was got when the vegetables were solar dried.

The solar drying therefore gave end product with a lower microbial load and therefore a longer shelf life than the sun dried vegetables. Over time during storage, there was no significant increase or decrease pattern in the microbial load over the eight weeks of storage for both the solanum aethiopicum and the amaranthus lividus that would indicate one of the processing techniques spoiled faster in comparison to the other. Therefore, the fresh vegetables had the highest nutritional quality followed by the solar dried vegetables and finally the sun dried vegetables.

The solar dried vegetables had the least microbial load and therefore longest shelf life as they were least prone to spoilage, followed by the sun dried vegetables. The fresh vegetables had the highest microbial load and so were the most prone to spoilage. From the results it could then be concluded that solar drying is a better means of preserving the vegetables since the solar dried vegetables had a lower microbial load than the sundried vegetables and also because the solar dried vegetables retained more of the ascorbic acid than the sun dried vegetables.

\section{RECOMMENDATIONS}

Vegetables are perishables and so their quality depreciates with time. For this reason they should be processed to reduce their susceptibility to depreciation. The reduction in water activity by sun drying and solar drying is a cheap and efficient way of prolonging the shelf life of African Indigenous vegetables by reducing the microbial load. More of the microbes are reduced with solar drying than with sun drying. However, with the above processing techniques comes a compromise in the nutritional quality of heat and light sensitive nutrients like ascorbic acid. Less nutrient loss is experienced in solar dried vegetables than in sun dried vegetables. Though the solar drying technique seems the better theoretical option, consideration must be taken into the fact that it requires a solar drier which is an added cost while sun drying completely relies on the natural sun and involves no added costs.

\section{Conflict of interests}

The author(s) declare no conflict of interest through that may include any of the following:

\section{Funding}

Research support for this work (including salaries, equipment, supplies, reimbursement for attending symposia, and other expenses) by any organization that may gain or lose financially through publication of the paper.

\section{Employment}

Recent (that is, while engaged in the research project), present or anticipated employment by any organization that may gain or lose financially through publication of the paper.

\section{Personal financial interests}

Stocks or shares in companies that may gain or lose financially through publication; consultation fees or other forms of remuneration from organizations that may gain or lose financially; patents or patent applications whose value may be affected by publication.

\section{REFERENCES}

Adams MR, Hartley AD, Cox LJ(1989). Factors affecting the efficacy of washing procedures used in the production of preparing salads. Food microbiology, 6, 69-77. 
Barrett DM(2008). Maximising the nutritional value of fruits and vegetables. Centre for excellence in Fruit and vegetable quality, University of California, Davis, CA 95616.

Beuchat LR(1996). Pathogenic microorganisms associated with fresh produce. J. food protection,52,204-216.

Brackett RE(1994). Microbial spoilage and pathogens in minimally processed refrigerated fruit and vegetables.(edited by Wiley, $R C$ ) $P$. 269-312. New York; Chapman and Hall.

Burnett SL, Beuchant LR (2001). Human pathogens associated with raw produce and un pasteurised juices, and difficulties in contamination. J.indus. Microbial . Biotechnol. 27: 104-110.

Enachesu MD (1995). The biodiversity of traditional leafy vegetables. International plant genetic resource institute, Rome, Italy. Pp 48 -57.

Ezell BD, Wilcox MS(1959). Loss of vitamin C in fresh vegetables as related to wilting and temperature. J. Agric. Food Chem. 7, 507-509.

Garg N, Churey JJ, Splittstoesser DF(1990). Effect of processing conditions on the micro flora of cut vegetables. Journal of food protection, 53,701-703.

Imungi j(1989). The role of indigenous vegetables in Human nutrition in Kenya. Paper presented at the indigenous Vegetation experience forum $\mathrm{Pp} 20-23$

Jay JM(1986). Modern food Microbiology. $3^{\text {rd }}$ edition. Vannostand Reinhold, Newyork: Wayne state University. Pp36-39.

Kirk RS, Sawyer R(1991). Pearson's composition and analysis of foods. UK; Longman Group; pp243.

Less Seung K, AA(2000). Preharvest and post harvest factors influencing vitamin C content of horticultural crops Post harvest Biology and Technology 20, 207-220.

Lester RN(2007). Taxonomy of scarlet egg plant solanum aethiopicum L, pp. 125-132. In: Van der Maesen, L.J.G. (Ed) Acta Horticulture 182, Taxonomy of cultivated plants.

Martin- Belloso and Lianos -Barnober.

Mills HA, Jones BJ(1996). Plant nutrition Hand bk 11, Micro Publishers, Athens, GA. Pp101-109.

Mukiibi JK (2001). Agriculture in Uganda. Volume 11 Crops. Fountain publishers/ CTA/NARO (2001). $1^{\text {st }}$ published 2001.Ottaway,P.B.,2002. The stability of vitamin during food processing. In: Henry C.J.K., Chapman, C. The Nutrition Handbook for food processors. Published by woodhead publishing limited, Abington Hall, Abington Cambridge CBI 6AH, England.
Nguye-the C, Carlin F (1994). The microbiology of minimally processed fresh fruits and vegetables. Critical reviews in food science and nutrition, 34, 371-401.

Okigbo BN (1977). Neglected plants of horticultural and nutritional importance in traditional farming systems of tropical Africa.

Parviainen MT, Nyyssonen K (1992). Ascorbic acdn In: Leenheer, A.P.D., Lambert, W.E., Nelis, H.(Eds.)., Modern chromatographic Analysis of vitamins.Marcel Dekker, New York.

Rubaihayo EB, Hart T, Kagonge E, Kaaya A, Kawongoto E, Kabeere F, Mugisha J, Tumusime J, Rubaihayo P (2002). Development of mechanisms for sustainable production and utilisation of indigenous vegetables and management of their genetic diversity in Uganda.

Singh G, Kawatra A, Sehgal S, Pragati(200). Effect $f$ storage on the nutritional composition of selected dehydrated green leafy vegetable, herb and carrot powders plant foods for human nutrition $58,(3), 1-9$.

Weerakkody WAP (2004). Nutritional value of fresh leafy vegetables as affected by pre-harvest factors. International society for horticultural science.

Wlliams CN, Uz JO, Peregrine WTH (1991). Vegetable production in the tropics. UK: Longman Group; pp2, 98.

Wills RBH, Wimalasiri P, Greenfield H(1984). Dehydroascorbic acid levels in fresh fruit and vegetables in relation to total vitamin $C$ activity. J Agric Food Chem. 32, 836-838.

World Bank, 2002. The contribution of Indigenous vegetables to house hold food security, http;//www.worldbank.org. 